awkward-looking fashion. I must have stayed and watched them for about twenty minutes, when out came the spider and descended the single line to the beetle, on which he boldly rushed; after a few seconds the beetle's struggles got weaker and weaker, when the spider returned to its den; in a few seconds more the struggles of the beetle ceased. Now, did the spider intend the beetle for its food when he cut away his web to save it from destruction from the beetle's struggles, or was that an after-thought, or why should he know it was a "creature comfort"? and was the fact of the line being so near the ground an accident, or was it premeditated? If you put a small pebble or small piece of wood in a web, a spider will let it drop altogether; if you put a grasshopper in it he rapidly turns it round till the creature looks like a mummy; but I suppose circumstances alter cases even with spiders.

JAMES R. GREGORY

THE following fact may be of interest to those of your readers who are connected with the correspondence in your columns regarding the possession of intellect by brutes.

Having been much worried by the depredations of bandicoots (Mus gigantens) I laid three pieces of bread for them smeared with Roth and Ringeisen's phosphor paste. Next morning the pieces of bread were found near the door where they had been placed but turned upside down. The bandicoot evidently was suspicious of the poison, had turned over the bread and nibbled away all the sound portion. On the next night I smeared the poison on very thin slices of bread, leaving hardly any of it free from the paste. On this occasion the caution of the bandicoot seems to have deserted it, for the bread was eaten, and the dead animal was found next day in the garden.

Bangalore, India, January 8

Elphinstone Begbie

\section{Suicide of the Scorpion}

Apropos of the discussion on this point that has lately taken place in NATURE, will you allow me to say that I tried the experiment referred to therein a score of times at least during my long residence in India, and that I never saw the phenomenon so graphically delineated by Byron. My experiments were conducted in cholera and other camps, in the open air, often in the presence of others, and always under circumstances which could admit of no doubt. The conclusion I came to in the matter was that "the scorpion girt by fire" is too stupid or too cowardly a creature to "cure its pain by darting its sting," or anything else, "into its desperate brain." It either rushed blindly into the flames at once, and was then and there destroyed or it wandered meaninglessly about the margin of "the circle," recoiling nervously from the actual contact, or retiring as far as it could from the heat, to resume, after a short respite, its old mancuvres. I believe as the result of these inquiries that the impression or belief created by the fine imagery of the great poet is a myth and nothing more.

Warrington

Will Mr. Gillman or some other tell us how scorpions achieve suicide? The animal stings, as I know to my cost, by a back ward lash out and straightening of the tail, and the force which drives the somewhat blunt point into the enemy goes on accumulating as the reversal becomes more complete, and reaches its maximum on or near the horizontal plane and at the furthest point of extension. But when the tail is drawn back above the animal's head, the point is turned upwards, and therefore away from the head, and even if it could be turned towards the head, there is no possible force to drive it through the tough or hard carapace.

Can a man pummel his own back? Can a horse kick its own belly? But the feat attributed to the scorpion, apart from it moral obliquity, is physically even more triumphant.

B.

\section{Stags' Horns}

OBSERVING in a late number of NATURE a communication concerning the disappearance of stags' horns after being cast off, and a request for information upon the subject from whatever source it might be had, I venture to send the following :-

A few winters ago I spent some weeks in the woods of Georgia, where most of my time was devoted to deer-hunting.
In roaming over the woody hummocks of that country I several times stumbled upon the cast-rff antlers of bucks. Being, like your correspondent, impressed with the popular belief that these were always buried or in some way destroyed by the animals, I inquired of old hunters if it was of common occurrence to meet with them, and was told that they were not rarely found just as we had seen them upon the occasion in question. I suppose that the popular belief in their burial or destruction arose out of the fact that about the time for shedding their horns the bucks retire to the most secluded spots accessible so as to avoid disturbance by other bucks or any enemy during the first few days of the tender, velvety stage of the new horns, and into such retired places man does not commonly venture.

This brings to mind the similar habit which prevails among most crustaceans. The edible crab of this region, for example, waits for a very high tide, and goes with it far inland, where, in shelter of some dark nook, and quite away from its common enemies, it slips off the old shell and spends a few hours on land awaiting the hardening process of the new one before entering again into the struggles of life. The fishermen have learned, however, that the most favourable times for catching soft crabs is connected with certain phases of the moon, to which they attribute some mysterious infuence upon the crabs directly; of course the dependence of tides and moon solves this little mystery.

Baltimore, Maryland, U.S.A., January 22

BOLLING W. BARTON

\section{MOUNTAIN BUILDING ${ }^{1}$}

$\mathrm{F} E W$ problems in physical geology are more fascinating than that which deals with the origin of mountains. At the same time few present greater difficulties. In the first place it is absolutely necessary to ascertain the facts of mountain structure before proceeding to frame any theory to account for them. Yet to do this involves an amount of mere physical toil which of itself raises a formidable impediment to progress. For the mountains cannot be understood from a distance. One may not intuitively interpret them by merely looking at them from below. They must be climbed and scrutinised in detail from crest to crest and valley to valley. But to be able to understand what one sees in these elevated regions, one must have an eye that has been well trained in the observation of geological structure, and which, while losing sight of no essential detail, can yet detect the dominant lines amid the apparent disarray of crag and scar, slope and pinnacle. In the next place, having elicited the fundamental facts, it is needful to find for them some explanation which, while connecting them harmoniously and Iuminously, shall be in strict accordance with the laws of physics, and from the point of view of geological dynamics may be regarded as not only possible but probable.

Thus two obvious paths lead to the consideration of the subject. "By the one we are conducted into the region of geological observation in the field. By the other we are drawn to the laboratory and the workshop, where the processes of nature can in some measure be repeated and watched. But these two roadways lie near each other, and the traveller along either of them, if he would keep himself from profitless divergence, should never lose sight of the other. Unfortunately this caution has not always been followed. Hence theories of mountain growth have been proposed, some of them wholly regardless of the real facts of mountain structure, others as defiant of physical possibilities.

Within the last few years the most detailed studies of the actual structure of mountains yet attempted have been carried out among the Alps. Chief among these are the admirable monograph of Dr. Baltzer upon the Glärnisch, and the still more remarkable and beautifully illustrated work of Prof. Heim, on the mechanism of mountainmaking. These two writers deserve the thanks of all who take interest in the many questions which the forms of the mountains never cease to raise in the mind. They I "Der Mechanismus der Gebirgsbildung." Dr. F. Pfaff. (Heidelberg. 1879.) 
have done much to supply what has all along been a fundamental defect in the conditions for the discussion of the problem - the want of detailed and carefully observed facts. But geologists will never be able satisfactorily to work out the problem until they construct large detailed sections on a true scale, vertical and horizontal, and insert upon them the thicknesses and angles of inclination of the rocks in their exact relations. It would be a task well worthy of the time and energy which any enthusiastic student of the science could bestow to run such a section across the Alps, or at least across some typical portion of the chain. The true outlines and related structure as thus determined, would make most of the existing diagrams of alpine structure appear as ludicrous exaggerations.

Among those who have essayed to follow in the wake of Sir James Hall, the founder of experimental geology, and to seek a solution of some of the problems of mountain building by well-devised experiments, Daubrée and Favre have in recent years been specially successful. Another experimenter has just appeared in the person of the accomplished Dr. Pfaff, of Erlangen. His previous works have shown him to possess no ordinary powers of scientific exposition, and in particular his "Allgemeine Geologie als exacte Wissenschaft" deserves the attention of geologists as a remarkably incisive criticism of their science in its present aspects. He is essentially an experimenter, who would reduce every geological problem if possible to the test of actual measurement and experiment. Some of his own practical work in this department is full of ingenuity and suggestiveness. $\mathrm{He}$ has now come forward as a disputant in the vexed question of the formation of mountains. His critical faculty, however, here shows itself rather destructive than constructive. He institutes numerous experiments to prove the inadequacy of previous theories, but he leaves us with very little that is satisfactory to put in their place.

As we read Dr. Pfaff's essay and note how he gravely argues as to the capabilities of rocks under pressure and the processes of mountain building, from what he has been able to do with a few square inches of limestone, a steel punch, and other appliances, we are reminded of the censure pronounced by Hutton on the temerity of those who "judge of the great operations of the mineral kingdom from having kindled a fire and looked into the bottom of a little crucible." He forgets that while much may be learnt from experiment, it must always be first of all determined how far the conditions of experiment resemble those of nature. Thus he takes a solid cylinder of Solenhofen limestone $4 \mathrm{~mm}$. in diameter, tightly titting into a hollow steel cylinder with a small aperture on one side, and subjects it to a pressure of 9,970 atmospheres for seven weeks. He then finds that the stone has not in the least degree been forced into the empty aperture prepared for it, and that its microscopic structure shows no sign of internal alteration or rearrangement. Accordingly he concludes that even with so high a pressure rock acquires no plasticity. With this conclusion no fault can be found until it is applied to the solution of problems in mountain structure. Surely Dr. Pfaff does not mean to affirm that there is any analogy between his solid cone of lomogeneous limestone tightly fitting into a steel cylinder and the alternations of various sediments differing so much in texture, structure, density, and inclosed water which constitute most of the visible part of the earth's crust. He does not seem to be aware of the fact that rocks have been experimentally proved to be plastic under much less pressure than he applied. We would recommend him to read the classical memoir of Sir James Hall and the researches of Daubrée and Tresca on the flow of solids. He will find also some convincing proofs in $\mathrm{Mr}$. Miall's paper on the contortion of rocks, that even on the surface, under every-day conditions, not inconsiderable curvatures of solid stone take place merely through gravitation. If he will visit this country we shall be happy to conduct him to some graveyards where the centres of vertically-placed slabs of Italian marble have, under the influence of weathering, been started out from their backing, so that they "belly" out like partiallyfilled sails.

Dr. Pfaff does not, of course, deny that rocks have been violently compressed and contorted, and he is no doubt well aware that their inclosed fossils have often undergone extraordinary deformation. He contends, however, that these are mere superficial phenomena, and endeavours to support and explain his contention by sections of the earth's crust, about which we venture to predict that Prof. Heim and his Swiss colleagues will have something to say before long. Dr. Pfaff has a theory of his own to explain curvature and deformation. He regards these as the results of the co-operation of water with gravity! Though hitherto no Neptunist, he now distinctly avows himself as a believer in the paramount power of water in the elevation of mountains. It is a pity that after more than a hundred pages devoted to the demolition of all our views as to the effects of terrestrial contraction due to secular cooling, he should tantalise us with a mere brief statement of his own theory. Perhaps it seems so self-evident to himself, that it needs no elaborate experiments to prove its truth, and no expanded statement to insure its acceptance. That a man at this time of day can honestly persuade himself that the upheaval of mountains, the plication, inversion, and deformation of rocks can be accounted for merely by the effects of subsidence due to the abstraction of materials from below by percolating water seems incredible. But that such a creed should be professed by one who has shown himself so good an observer and so acute a reasoner, is still more astonishing. When, after perusing the greater part of his book, and noting argument after argument, and experiment after experiment brought forward to upset all accepted theories on the subject, one comes suddenly and without warning upon his own theory, it is as if some rogue had incontinently put the lamp out. One does not know what to make of the situation. There is something too ludicrous about it. Serious argument is no longer possible. Dr. Pfaff must be bantered out of his hydropathic geology. His abilities are too great to be lost in a monomania of this kind. We would reccmmend for his speedy restoration to geological sanity a trip into Switzerland, under the care of Drs. Baltzer and Heim. This treatment, if taken in time, will, no doubt, restore him at least to such measure of health as can be enjoyed by a man who works out his geology ia his study and laboratory rather than in the field.

A. G.

THE SWEDISH NORTH-EAST PASSAGE EXPEDITION

THE following notes are taken from a letter from Prof: Nordenskjold to Mr. Oscar Dickson, dated Ceylon, December 16, 1879, printed in the Göteborgs Handel's Tidning:-

Dredging was carried on at a number of places on the coast of Japan, but with scanty results, in consequence of the poverty of the sea-bottom in animal life. The same was the case with the dredgings which were carried on between Hongkong, Labuan, and Singapore, and in the Strait of Malacca, although the bottom consisted in some places of clay, in others of sand, coral-sand, or rock, and thus ought, at least at some of the places, to be favourable to the development of a rich animal life. While the trawl-net in the Polar Sea almost always brought up several hundred animals, the zoologist in these southern seas obtained seldom more than one or two at each draw, and frequently not one. By far the most abundant animal life has been found during the Swedish Arctic expeditions, at favourable places in the 